\title{
Epicardial Fat and Hepatic Steatosis as Cardiovascular Risk Markers
}

\author{
Grasa epicárdica y esteatosis hepática como marcadores de riesgo cardiovascular
}

GASTON A. RODRIGUEZ-GRANILLO ${ }^{1,2}$ (D), DIEGO ARUFE ${ }^{3}$ (D) , GABRIELA BERG ${ }^{2,4}$ (D)

\begin{abstract}
Epicardial adipose tissue (EAT) is a metabolically active tissue which has raised great interest in the last decade as a cardiovascular risk marker. It is related with the production of proinflammatory cytokines and free fatty acids, the promotion of a state of hypercoagulability and with numerous cardiometabolic risk factors. Between EAT and coronary arteries, there is not only an intimate anatomical association, but also bidirectional physiological aspects of paracrine regulation. In addition, several studies have found a relationship between EAT and endothelial dysfunction, non-obstructive atheromatosis, oxidative stress, atrial fibrillation and diastolic dysfunction.

Parallel to these findings, there is a tight association between hepatic steatosis (the most prevalent chronic hepatic disease), coronary atheromatosis and cardiovascular risk. One of the interesting and differential characteristics of hepatic steatosis with respect to coronary artery disease is its dynamic, and to a certain point reversible, character.

Despite their association with atheromatosis and cardiovascular risk, and simple assessment from non-invasive imaging methods, epicardial fat and non-alcoholic fatty liver are seldom considered as risk markers in clinical practice.
\end{abstract}

Key words: Atherosclerosis - Adipose Tissue - Body Mass Index - Computed Tomography - Fatty Liver - Inflammation - Pericardium - Risk Factors

\section{RESUMEN}

El tejido adiposo epicardico (TAE) es un tejido metabólicamente activo que ha cobrado gran interés en la última década como marcador de riesgo cardiovascular. El TAE se relaciona con la producción de citoquinas proinflamatorias y de ácidos grasos libres, con la promoción de un estado de hipercoagulabilidad, y con numerosos factores de riesgo cardiometabólico. Existe una íntima relación entre las arterias coronarias y el TAE, no solo anatómica, sino en cuanto a aspectos fisiológicos bidireccionales de regulación paracrina. Además, numerosos estudios han encontrado una relación entre el TAE y la presencia de disfunción endotelial, ateromatosis no obstructiva, estrés oxidativo, fibrilación auricular, y disfunción diastólica.

En paralelo, existe una estrecha relación entre la esteatosis hepática (la enfermedad hepática crónica más frecuente), la ateromatosis coronaria, y el riesgo cardiovascular. Una de las características interesantes de esteatosis hepática y diferenciales con respecto a la enfermedad coronaria es su carácter dinámico y, en cierta medida, reversible.

A pesar de las asociaciones descriptas con la ateromatosis y con el riesgo cardiovascular, y de su evaluación sencilla a partir de métodos de imagen no invasivos, la grasa epicárdica y el HGNA son raramente considerados como marcadores de riesgo en la práctica clínica.

Palabras Clave: Aterosclerosis - Tejido Adiposo - Índice de masa corporal - Tomografía Computarizada - Hígado graso - Inflamación - Pericardio - Factores de Riesgo

\section{Abbreviations}

\begin{tabular}{|c|c|}
\hline BMI & Body mass index \\
\hline CAC & Coronary artery calcification \\
\hline CRF & Cardiovascular risk factors \\
\hline CTCA & Computed tomography coronary angiography \\
\hline EAT & Epicardial adipose tissue \\
\hline EFV & Epicardial fat volume \\
\hline FFA & Free fatty acids \\
\hline FAI & Fat attenuation index \\
\hline HFpEF & Heart failure with preserved ejection fraction \\
\hline HRP & High-risk plaque \\
\hline
\end{tabular}

REV ARGENT CARDIOL 2020;88:334-344. http://dx.doi.org/10.7775/rac.v88.i4.18387

Address for reprints: Instituto Medico ENERI, Clínica La Sagrada Familia - Av. Libertador 6647 (C1428ARJ) Buenos Aires, Argentina

E-mail: grodriguezgranillo@gmail.com

\footnotetext{
${ }^{1}$ Instituto Medico ENERI, Clínica La Sagrada Familia

${ }^{2}$ National Scientific and Technical Research Council (CONICET)

${ }^{3}$ Hospital Universitario Austral. Hepatology and Liver Transplant Unit. Sanatorio Sagrado Corazón. Hepatology and Liver Transplant Unit

${ }^{4}$ Buenos Aires University, School of Pharmacy and Biochemistry, Physiopathology and Clinical Biochemistry Institute (INFIBIOC), Department of

Clinical Biochemistry, Lipid and Atherosclerosis Laboratory, Buenos Aires, Argentina
} 


\section{INTRODUCTION}

Epicardial adipose tissue (EAT) is the intrathoracic visceral fat depot located between the myocardium and pericardium in intimate contact with the coronary arteries. Historically considered a simple energy deposit, EAT is a metabolically active tissue which has raised great interest in the last decade as a cardiovascular risk marker. (1) Both EAT and abdominal visceral adipose tissue, with the same embryological origin, are related with the production of proinflammatory cytokines and free fatty acids (FFA), promoting a state of hypercoagulability and numerous cardiometabolic risk factors. (2-4) Specifically, diabetic patients present larger EAT volume, with a proinflammatory and metabolically more active profile independently of other cardiovascular risk factors (CRF) (5-7)

The role of EAT in the development and progression of coronary atheromatosis has been demonstrated not only through the severity but also by the presence and extension of non-obstructive atheromatosis $(8,9)$ Concurrently, numerous studies have found a relationship between these fat depots and the incidence of endothelial dysfunction, atrial fibrillation, and diastolic dysfunction. (10-13) More recently, it has been shown that EAT does not have a homogeneous composition and distribution, and that these differences are associated with regional changes in the composition of adjacent atherosclerotic plaques, especially regarding the presence of coronary inflammation. (14-16)

In addition, there is a close relationship between hepatic steatosis (HS), coronary atheromatosis and cardiovascular risk. Hepatic steatosis is the most frequent chronic liver disease, with an estimated $20 \%$ to $30 \%$ prevalence in the general population. It is the second cause of liver transplant, (17) and is closely associated with the different components of metabolic syndrome. (18) Moreover, several studies have shown a relationship between HS and visceral fat, but it is still unclear whether it has an active role in the development and progression of atheromatosis or its presence only reflects the coexistence of other cardiometabolic risk markers.

Despite the implementation of improved prevention strategies, residual cardiovascular risk is partly attributed to coronary inflammation; therefore, it would be very important to incorporate monitoring tools and vulnerability markers to assess both the acute inflammation and chronic vascular and perivascular changes. (19-21)

\section{Limitations of general obesity markers}

Elevated cardiovascular morbidity and mortality in obese patients compared with the general population is mostly linked to their association with multiple CRF. (22, 23) However, general obesity markers, as body mass index (BMI), present multiple limitations that have globally led to inconsistent and even divergent results regarding their ability to predict events. Effectively, numerous studies have demonstrated a negative relationship between BMI and coronary artery disease, as well as a debatable association between obesity and survival, particularly in elderly adults. (24, 25) This controversial or paradoxical behavior is in part due to the defective definition of obesity based on BMI, a poor adiposity index as it is more a surrogate of weight than body fat, which cannot identify the proportion of the different regional body fat depots related with cardiometabolic profiles and divergent prognoses. (26-28) Even waist circumference presents limitations and occasionally contradictory results regarding its predictive value. $(29,30)$ This is possibly attributed to the fact that abdominal obesity was originally defined through BMI as a reference value and not by its relationship with the risk of events, and that despite being an approximate estimation of abdominal fat, the assessment of waist circumference does not differentiate between subcutaneous and visceral fat. This previously ignored disquisition is essential in view of current evidence showing that only visceral and not subcutaneous fat is associated with the incidence of heart failure with preserved ejection fraction (HFpEF). (31)

\section{Pathophysiological aspects of epicardial fat}

In addition to adipocytes, adipose tissue consists of stromal cells (fibroblasts and inflammatory cells) and interstitial tissue. Adipose tissue produces a great number of molecules, including pro- and anti-inflammatory cytokines, fatty acid metabolites and reactive oxygen species which regulate numerous physiological aspects of adjacent tissues. (32) Compared with other visceral adipose tissues, EAT is characterized by increased fatty acid synthesis and catabolism, so it has been proposed as a "buffer" fat that protects the heart against cardiac steatosis generated by FFA. (33) However, with EAT expansion and inflammation, the "cross-talk" between both tissues would be altered with interaction between pro-inflammatory adipocytokines and the intramyocardial fat depot which also accompanies the insulin resistance (IR) process. (34) We have recently demonstrated that in patients with coronary artery disease and type II diabetes, higher activity of triglyceride-rich lipoprotein catabolic enzymes would promote increased FFA flow into the tissue, favoring EAT expansion. (5)

Specifically, perivascular EAT has a paracrine action on coronary arteries, regulating multiple aspects of vascular biology, including inflammation [with pro-inflammatory cytokine (IL-1 $\beta$, IL-6 and TNF- $\alpha$ ) and chemokine (MCP-1) secretion], vascular tone, oxidative stress and local nitric oxide production (Figure 1). (32, 35, 36) Epicardial adipose tissue can secrete both pro-inflammatory (leptin, resistin) as anti-inflammatory (adiponectin) adipokines, and their balance depends on the degree of tissue inflammation and expansion. Recent evidence suggests that perivascular fat (PVF) could act as a thermometer of underlying atherosclerotic plaques, detecting 


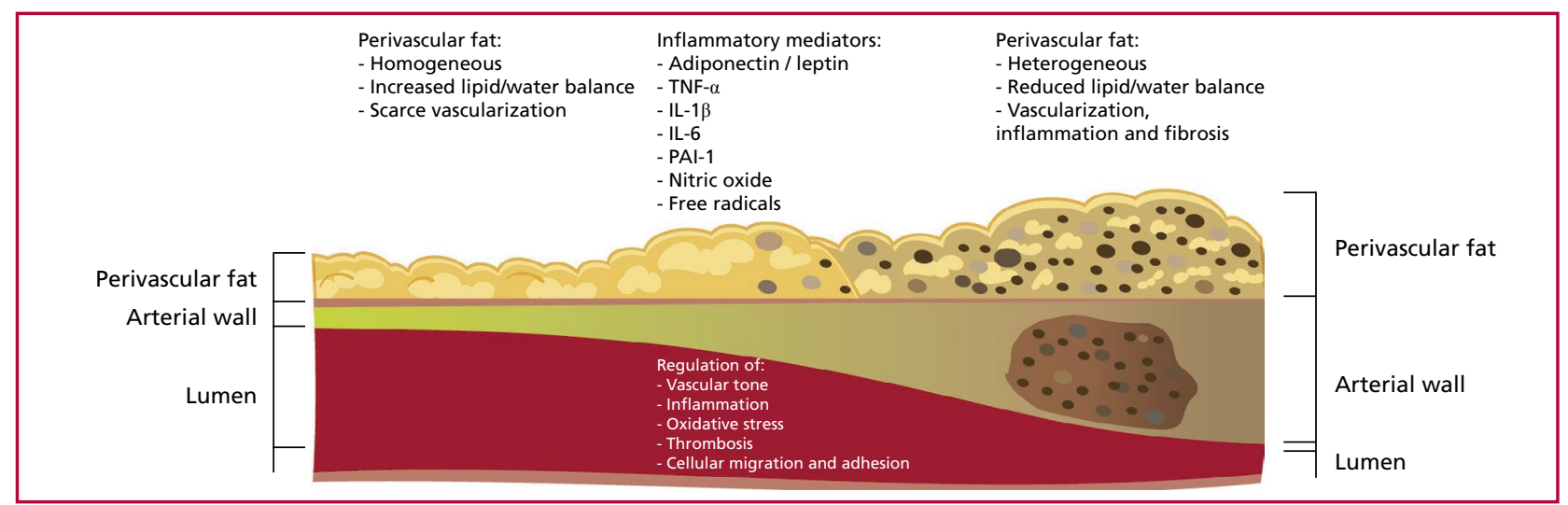

Fig. 1. Role of perivascular fat (PVF) in the development and progression of coronary artery disease. In the healthy vessel, PVF is homogeneous, with lipid-rich adipocytes (scarce fluid), scant vascularization and very few inflammatory cells. As lesions develop, PVF becomes heterogeneous, adipocytes decrease in size due to reduced fat content and lower cellular differentiation, with increased aqueous phase and evidence of increased vascularization, inflammatory cells (including macrophage polarization to a higher concentration of M1 activated macrophages) and fibrosis. A lipidic-necrotic nucleus starts developing at the intima level with foam cells and microcalcifications, and both media (with positive coronary remodeling) as well as fibrous cap thinning. These bidirectional phenomena (from the arterial wall towards PVF and vice versa), are mediated by numerous vasoactive substances that regulate vascular tone, inflammation, oxidative stress and coagulation (PAI-1). IL: interleukin. TNF: tumor necrosis factor. PAl-1: Plasminogen activator inhibitor-1.

local changes in oxidative stress and acting accordingly (for example, secreting adiponectin in the presence of increased oxidative stress). In addition, in the presence of local coronary inflammation and the ensuing cytokine diffusion to the perivascular interstitial space, the lipidic adipocyte content is reduced and the aqueous/edema phase of PVF increases. (37) Therefore, there is an intimate relationship between coronary arteries and EAT, not only anatomically but also in bidirectional physiological aspects (Figure 1). In the presence of an expanded and dysfunctional EAT, the pro-inflammatory effect of epicardial fat acts not only on the underlying vessel; pro-inflammatory mediators are also released to blood flow, and although the volume of EAT is much lower than that of abdominal visceral adipose tissue, it contributes to the systemic pro-inflammatory state. In addition, completing this bidirectional cycle, systemic inflammation promotes the accumulation and inflammation of epicardial fat. (38) It is not a coincidence that patients with diseases associated with systemic inflammation, as psoriasis, rheumatoid arthritis, HIV or obesity, have a significant increase of EAT (39-41)

One of the most paradigmatic aspects generating hypotheses about the association between epicardial fat and atheromatosis stems from the study of myocardial bridges and experimental research in animals with epicardial fat resection. In the former, there is characteristic absence of atheromatosis at the level of the intramyocardial segment. (42) In a study evaluating coronary anomalies by computed tomography coronary angiography (CTCA) in 109 myocardial bridges, none of the intramyocardial segments had signs of atheromatosis, despite its presence in $65 \%$

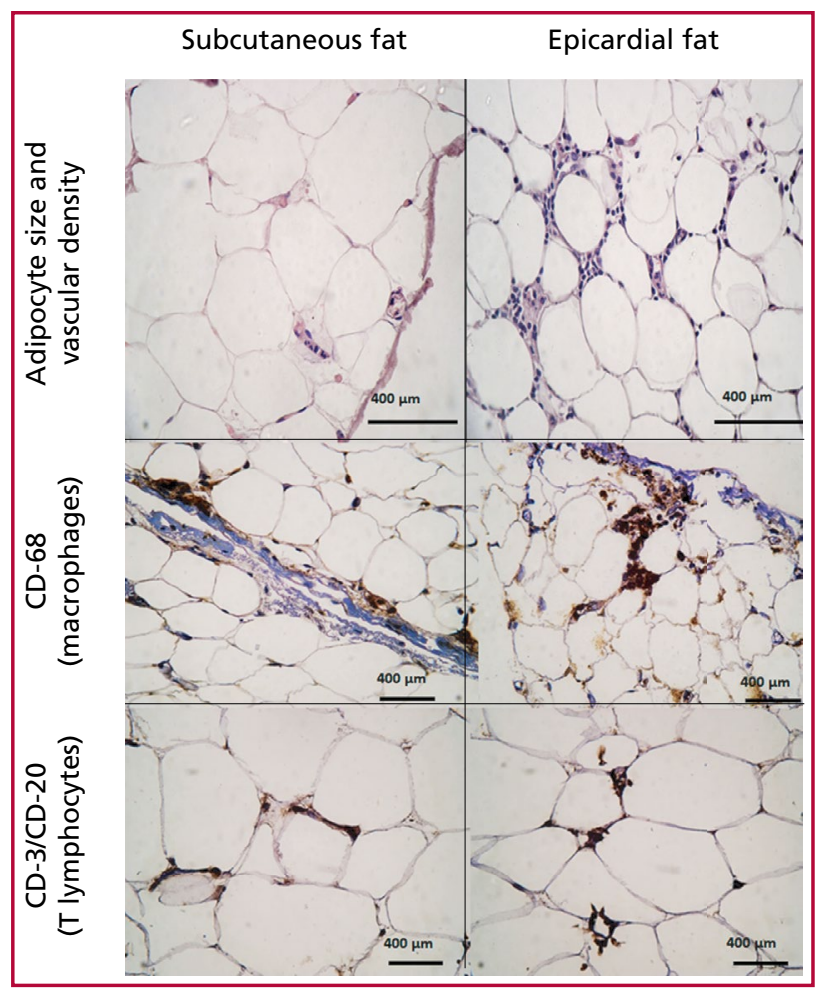

Fig. 2. Histological characteristics and inflammatory infiltrate of epicardial adipose tissue (EAT, upper right ventricular area) and subcutaneous adipose tissue (SAT, thoracic area), obtained from patients with coronary artery disease referred for myocardial revascularization surgery. Epicardial adipose tissue adipocytes are smaller and the tissue is more vascularized than that of SAT. Immunohistochemical studies show that EAT presents macrophage (CD68+) and lymphocyte T (CD3/CD20) infiltrates. The brown dye indicates positive immunochemistry. 
of hosting vessels. (43) In an elegant study that included epicardial fat resection adjacent to the middle third of the anterior descending coronary artery in pigs under atherogenic diet and with serial evaluation by intravascular ultrasound, McKenney et al. identified progression of atheromatosis in the proximal and distal segments, without significant changes at the level of the segment without EAT. (44) There is even macrophage polarization with a higher concentration ratio between activated macrophages (M1) and macrophages with anti-inflammatory properties (M2) in the EAT of patients with coronary artery disease compared with patients without this disease. (45) Effectively, it has also been demonstrated that EAT of patients with coronary artery disease present enhanced vascular density, macrophage infiltration and type 2 and 9 metalloproteinase (MMP) activity, the main enzymes in charge of atherosclerotic plaque degradation and also linked to coronary remodeling (Figure 2). (46) These enzymes participate in EAT expansion, although their ability to migrate towards underlying atherosclerotic plaques to increase their vulnerability remains to be proved.

On the other hand, and for reasons still unknown, subcutaneous adipose tissue has been associated with lower risk of coronary and peripheral atheromatosis and mortality. (47-49) In a seminal work including patients with elective coronary bypass graft surgery, Mazurek et al. collected paired samples of EAT adjacent to the proximal third of the right coronary artery and of subcutaneous cellular tissue adjacent to saphenous veins, and compared the expression of different inflammatory markers. (50) In this study, EAT showed significantly higher levels of inflammatory mediators than subcutaneous fat, including IL-1, IL-6, TNF- $\alpha$, and MCP-1, independently of obesity, diabetes or basal medication. Septal thickenings and inflammatory cellular infiltrates were identified in the cellular content of EAT, including, T lymphocytes, macrophages and mastocytes, while no inflammatory cells were identified in subcutaneous fat. In addition, no associations were found between this local inflammation and cytokine plasma levels.

Recently, the molecular and lipidomic study of EAT biopsies showed that patients with coronary artery disease present a lipidomic profile with prevalence of pro-inflammatory lipids, higher ceramide, diglyceride (saturated and monounsaturated) and monoglyceride concentration than patients without this disease. (51)

Therefore, EAT functions as an endocrine organ intimately linked with cardiovascular risk through inflammatory regulation.

In a parallel population study, including 3,291 asymptomatic subjects with mean age of 50 years, Sung et al. identified the association between visceral fat (EAT, periaortic fat and HS) and presence of inflammatory markers as C-reactive protein and neutrophil/lymphocyte ratio. (4) In addition, this work demonstrated an association between the severity of
HS and other markers of visceral adiposity as inflammatory markers.

\section{Pathophysiological aspects of hepatic steatosis}

Hepatic steatosis is the result of liver-synthetized triglyceride accumulation from FFA released by adipose tissue (lipolysis), excess carbohydrates (de novo lipogenesis) or excess triglycerides in the diet. (52) Nonalcoholic fatty liver (NAFL) is defined as the presence of steatosis ( $>5 \%$ of hepatocytes by histological analysis) in the absence of secondary causes that may generate it, as chronic alcohol consumption, chronic infection due to viral hepatitis, medications (e.g. corticoids, methotrexate, valproate, etc.) or autoimmune hepatic diseases. (53) The underlying pathophysiological mechanism for NAFL is associated with altered intermediate metabolism (lipids and glucose) and IR. (18) Insulin is a lipogenic hormone and in normal conditions suppresses hepatic gluconeogenesis. (54) Insulin resistance is greater in subjects with NAFL and has a central role in its development and progression. (55) One consequence of IR is the increase of peripheral lipolysis, mainly of visceral adipose tissue, with increased serum levels of FFA, leading to a rise in hepatocyte toxic lipids, such as diacylglycerols and ceramides which are involved in inflammatory pathways. The histological spectrum of NAFL extends from simple steatosis to steatohepatitis, fibrosis and cirrhosis (Figure 3).

Although the mechanism is not well elucidated, it is believed that the association between NAFL and atherosclerosis is linked to multiple factors differently involving IR, alteration of lipoprotein metabolism, low-degree inflammation, oxidative stress and decreased adiponectin levels (Figure 3) (57-59)

The activation of the NF-kB pathway in patients with steatohepatitis leads to an increase in the transcription of various pro-inflammatory genes. (60) In the same line, numerous inflammatory (C-reactive protein, IL-6 and TNF- ), oxidative and procoagulant [plasminogen activator inhibitor-1 (PAI-1), fibrinogen and factor VII] markers are found in patients with steatohepatitis. (61) A recent sub-analysis of the Multi-Ethnic Study of Atherosclerosis (MESA) population, which included 668 asymptomatic individuals with NAFL, showed that among many biomarkers (including C-reactive protein), IL-6 was the independent predictor of both coronary artery calcification (CAC $>0$ ) and moderately extensive coronary calcification (CAC >100). (62) Concomitantly, and in line with the mechanisms described at the epicardial fat level (Figure 1), elevated levels of PAI-1 in early adulthood are independently associated with NAFL in the second half of life. (63)

\section{Epicardial fat assessment by imaging methods}

Epicardial fat can be quantified with diverse precision through several non-invasive methods, including transthoracic echocardiogram, magnetic resonance 
imaging (MRI), computed tomography (CT) and positron-emission computed tomography (PET), unenhanced TC scan being the reference method due to its speed, availability, greater spatial resolution and volumetric acquisition (Figures 4 and 5). (64)

The simple identification of epicardial fat with CT scan [with a lower limit ranging between -190 and -250 Hounsfield units (HU), and an upper limit between -30 and $-50 \mathrm{HU}$ ] has led to the development of tools that allow the automatic assessment of epicardial fat volume (EFV) using artificial intelligence algorithms with accuracy comparable to that of expert reviewers. (65) There are no well-established boundaries for EFV evaluation, although most studies use the pulmonary artery bifurcation or the point situated 15 $\mathrm{mm}$ above the cranial border of the left main coronary artery as superior limit and the diaphragm as inferior limit. (64) Evaluation of EFV can be achieved using both unenhanced cardiac CT scan (calcium score) and contrast-enhanced CTCA, though in the latter case it is suggested to increase the detection threshold to -15 HU, since contrast-enhanced studies usually underes- timate fat by $30 \%$. $(64,66)$ Also, conventional unenhanced, non-ECG gated thorax CT scans (Figure 4) are equably reproducible and present the same predictive value as gated studies (Figure 5). (67, 68)

It should be mentioned that pericardial adipose tissue (PAT) includes both EAT and paracardiac fat tissue (outside the pericardial sac). Although it is of simpler assessment, closely related with EAT and with prognostic value demonstrated in numerous prospective studies, there are significant embryological and structural differences between paracardiac and epicardial adipose tissue. $(16,69)$

Regardless of the assessment strategy used, one of the major limitations in the use of EFV as a risk marker in clinical practice is the absence of normal and cutoff point standardized values, with reported significant differences according to populations, sex and body surface area. $(68,70)$

Non-invasive assessment of hepatic steatosis

There are several non-invasive methods for HS identification, with different precision, availability, cost,
Fig. 3. Natural history of the non-alcoholic fatty liver (NAFL). The main risk factors which condition the development of steatosis are obesity, hypercaloric diet and fructose consumption (sugar component and main component of high-fructose corn syrup) and factors favoring steatohepatitis, fibrosis and cirrhosis are obesity, components of the metabolic syndrome and diabetes. The lower panel depicts the relationship between NAFL progression, atherogenesis and risk of cardiovascular events. Inflammation, procoagulant factors and atherogenic lipids increase as the hepatic disease progresses, promoting the development of atheromatosis and cardiovascular events.

Fig. 4. Quantification of epicardial fat, assessment of coronary artery calcification and identification of hepatic steatosis by conventional chest CT scan. Notice the presence of calcification at the level of the anterior descending artery, with increased epicardial fat volume (in blue) and severe hepatic steatosis (10 HU and 0.21 liver/spleen ratio).
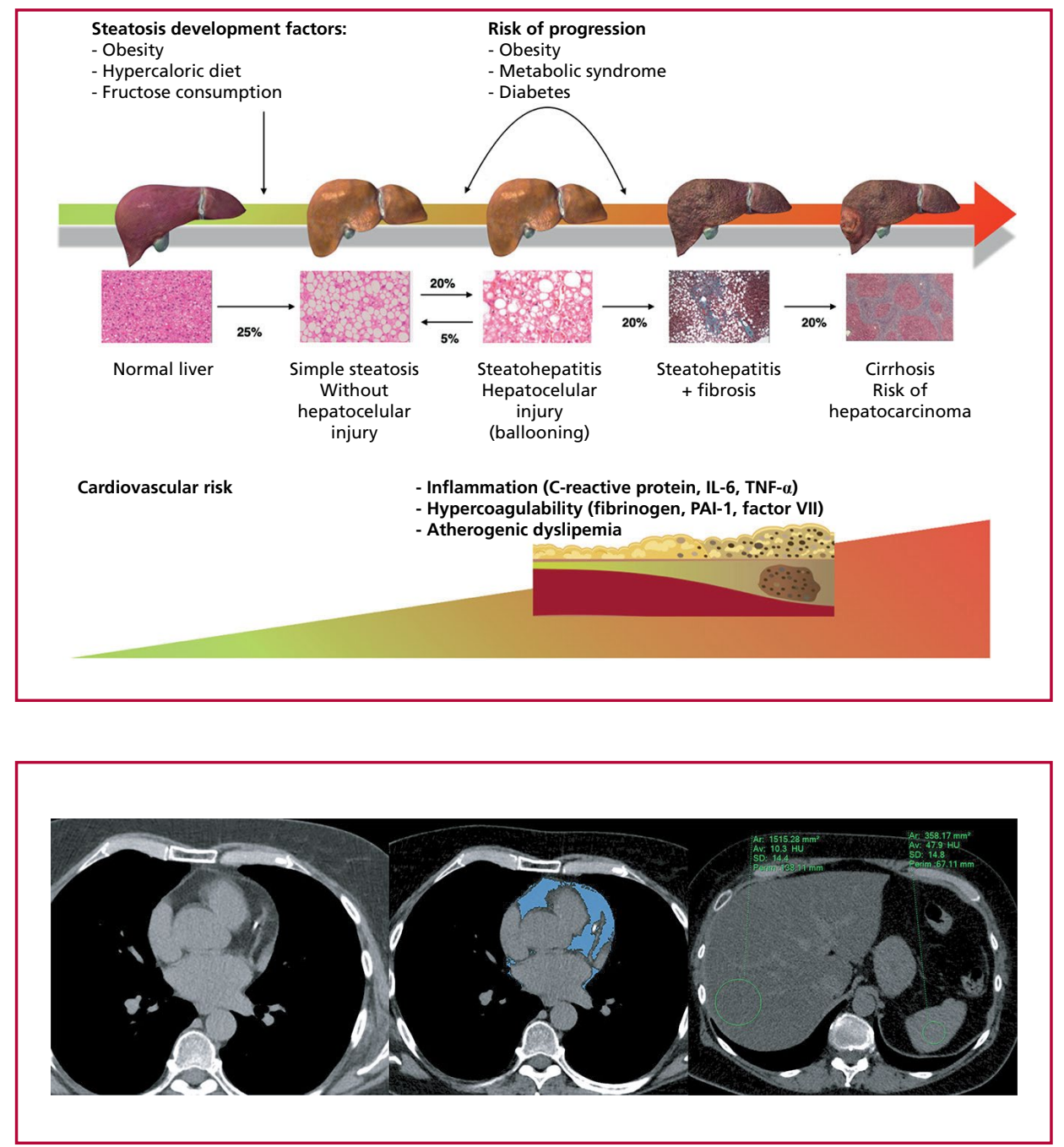


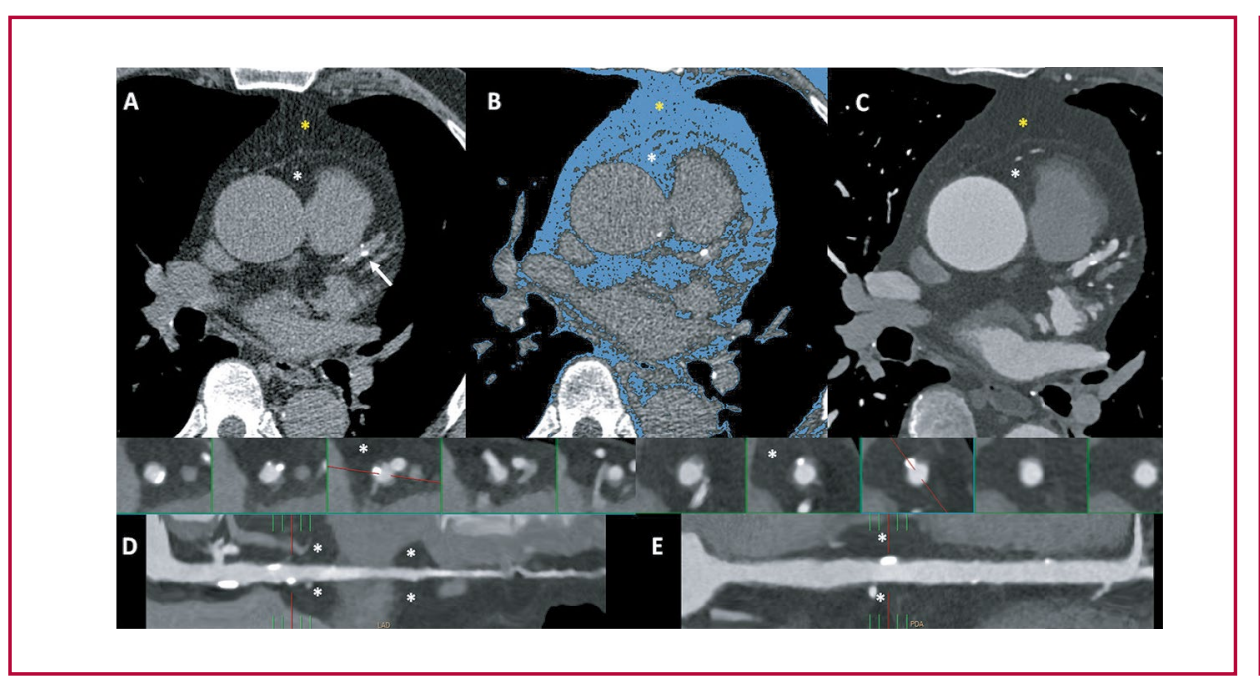

Fig. 5. Calcium score (panels $A$ and $B$ ) and CT coronary angiography (panels C-E) in a hypertensive 72-year old male patients with atypical chest pain. Both the unenhanced study (calcium score) as the coronary angiography allow the discrimination between epicardial fat (white asterisk) and paracardiac fat (yellow asterisk), as well the calculation of their volume and density. Multiplane reconstructions of the anterior descending (panel D) and right coronary (panel E) arteries are used to assess perivascular fat (asterisk).

sensitivity and specificity. (71) Conventional ultrasound is a widely available, non-expensive tool, very useful for screening through qualitative assessment. However, it has low sensitivity to detect histological steatosis below $20 \%$. Computed tomography, of similar sensitivity, is more specific and allows steatosis quantification and focal steatosis detection. In unenhanced studies, normal liver attenuation levels are between 50 and $65 \mathrm{HU}$, and generally 8 to $10 \mathrm{HU}$ higher than those of the spleen. Among different cutoff points to detect HS, the most accepted attenuation level limits are below 48 to $51 \mathrm{HU}$ (and lower than in the spleen). The MESA study group, among others, uses a simpler definition consisting in the presence of a liver (UH)/ spleen $(\mathrm{UH})$ attenuation ratio $<1$. (62) An attractive CT feature is the ability to evaluate within the same scan the upper portion/hepatic parenchyma dome, the extension and distribution of coronary calcification and EAT (Figure 4).

Magnetic resonance imaging is the most accurate method to assess HS, although it is less available, more expensive, has longer acquisition time and it is difficult for the evaluation of patients with very high BMI and/or claustrophobia. Each of these three modalities has evolved in the last years, developing specific techniques to evaluate NAFL which exceed the present article.

Relationship between epicardial fat and non-coronary artery disease

Some studies have described a relationship between EAT and atrial fibrillation (AF), (10, 72) which although not yet clearly defined, has been attributed to probably mixed mechanisms differently related not only to the diffusion of the already mentioned pro-inflammatory factors, but to external mechanical compression with reduced compliance and ventricular diastolic dysfunction due to myocardial fibrosis. $(38,73)$ In a study including patients with planned ablation, pericardial fat volume $(\mathrm{PFV})$ was associat- ed with the presence, severity and recurrence of AF, independently of general parameters of obesity. (74) Concurrently, in a recent study, van Woerden et al. identified higher EAT volume in patients with HFpEF compared with a control group, independently of BMI. In addition, EAT was associated with the presence of type 2 diabetes, AF and several inflammatory markers. (75) It has even been postulated that HFpEF with identified heart rate in obese patients can be attributed to the presence of microvascular dysfunction and altered myocardial relaxation related in different degrees to myocardial fibrosis, dilatation and AF, and a pro-inflammatory state associated with increased EAT. (76) The recent finding of a significant correlation between EAT and both myocardial lipid content and interstitial fibrosis suggests that, effectively, EAT somehow infiltrates the myocardium. (77)

Moreover, EAT inflammation can synthetize aldosterone, which not only perpetuates the inflammatory state and promotes fibrosis, but also favors volume overload, worsening HFpEF. (38)

Relationship between regional fat depots, atheromatosis and events

There is consistent evidence associating EAT with atheromatosis markers. Even some studies suggest that accelerated atheromatosis commonly present in HIV positive patients could be attributed to increased EAT in this population. (78) We have recently shown a significant relationship between pericardial and visceral fat with coronary and extra-coronary atherosclerotic plaque burden, while general adiposity markers, including CT-calculated total body fat volume, were not related with atherosclerotic burden. (49) These findings are in line with a large number of studies evidencing that EAT was not related with general fat depots but with coronary and extra-coronary atheromatosis markers, independently of CRF. (1-3) In the Heinz Nixdorf Recall study, which included 4,093 individuals between 45 and 75 years of age with known cardio- 
vascular disease, subjects in the upper EAT quartile presented significantly higher risk of hard events after an 8-year follow-up, even following adjustment by CRF (HR 1.54; 95\% CI 1.09-2.19) and calcium score (HR 1.50; 95\% CI 1.07-2.11). (79) This last finding, in line with results from other studies, supports the concept that the relationship between epicardial fat and vascular events would have different mechanisms than those of risk associated with coronary calcification. In a cohort including 998 individuals between 45 and 85 years from the MESA study, a significant association was found between PFV and risk of coronary events, independently of CRF and BMI (HR 1.26; 95\% CI 1.01-1,59), while no significant relationships were registered between events and BMI or waist circumference. (80) In the smaller Rancho Bernardo Study $(\mathrm{n}=343)$ but followed-up for 12 years, patients in the upper tertile of PFV presented 2.6 higher global mortality risk than those in the lower tertile, independently of CRF. (81) The EISNER study, in 456 asymptomatic individuals with mean age of 60 years demonstrated a significant relationship between EAT and coronary calcification. (82) The predictive capacity of PFV has also been shown by conventional chest CT scan. In a retrospective cohort including 1,250 patients with clinically indicated chest CT scan, we identified PFV as an independent predictor of all-cause mortality. (68)

Relationship between fat composition and event occurrence Computed tomography coronary angiography evaluates high-risk plaque (HRP) characteristics, such as positive remodeling, low-attenuation plaques $(<30 \mathrm{HU})$, signs of annular enhancement and microcalcifications. (83) Recently, a meta-analysis published by Nerlekar et al. showed the relationship between EAT extension and presence of HRP (OR 1.19; $95 \%$ CI 1.06-1.33). (84)

However, structural changes both at the coronary or PVF levels, that may be viewed by methods such as CT scan, would indicate more advanced stages of the disease than molecular or functional changes. This has prompted the search of noninvasive approaches that would allow an early detection of metabolic changes. It has already been mentioned that EAT distribution and composition is not homogeneous and that it is associated with the presence and distribution of atheromatosis and risk of events. These local gradients can be accurately discriminated by CT scan, assessing PVF density (HU) (the higher density fat, closer to zero, reflecting a lower lipidic content and presence of edema, greater vascularization and/or fibrosis). (14-16)

Goeller et al. reported significantly higher PVF attenuation levels in culprit lesions of patients with acute coronary syndrome compared with non-culprit lesions (-69.1 HU vs. $-74.8 \mathrm{HU} ; \mathrm{p}=0.01$ ) and even compared with control severe lesions (-76.4 HU; $p=0.01)$. (85)

It is thought that these CT-detectable changes in
PVF composition (Figure 1) precede the formation of coronary plaques, their early detection being highly important as most plaque ruptures and coronary events generally have non-obstructive lesions as substrate. $(14.15,83)$ In this respect, complex analyses that include genetic studies, immunomarkers and advanced tomographic evaluations (assisted and then trained with machine learning tools) based on cardiac surgery biopsies, with posterior validation in large prospective studies, identified pericoronary fat attenuation index (FAI) and radiotranscriptomic profile of pericoronary fat (RPF) texture with ability to detect the presence of coronary inflammation. (15)

This group of Oxford investigators validated FAI as a coronary inflammation marker associated with worse prognosis in two large prospective cohorts of completely different populations (Figure 6) In the CRISP-CT study, a higher FAI (less negative) of - $70 \mathrm{HU}$ was identified as a robust predictor of cardiac and allcause mortality, independently of demographic data, EAT, atheromatosis extension and HRP (14) In this study, FAI, also validated against PET CT scan, predicted the occurrence of major cardiovascular events even before plaque development. (37) Pericoronary fat attenuation index (Figure 6) is not only a sensitive but also a dynamic marker of coronary inflammation, being reduced by statin and aspirin administration. (14) Chronic changes in PVF, associated with fibrosis and microvascular remodeling, can be assessed through RPF texture assisted by machine learning algorithms. (86)

These characteristics were validated in 1,575 patients of the SCOT-HEART trial, with improved prediction of major events independently of CRF, calcium score, severity and HRP assessed by CTCA. (15) It must be pointed out that both FAI, reflecting acute changes (inflammation), as RPF, indicating chronic structural changes, are acquired by conventional CTCA. Therefore, these complementary methods may be possibly combined in a single CTCA study, together with multiple known evaluations and with independent prognostic value.

Relationship between hepatic steatosis and cardiovascular risk

Simple HS has a good prognosis, However, patients who develop steatohepatitis are at greater risk of chronic hepatic disease progression (fibrosis/cirrhosis). (87) Age (>50 years), type II diabetes, obesity and metabolic syndrome have been identified as factors associated to the progression of simple steatosis to steatohepatitis. (88) In patients with NAFL, cardiovascular disease is the most prevalent cause of death, regardless of the liver disease stage. (89) This increase of cardiovascular risk has been associated with different mechanisms, including the promotion of atheromatosis, arrhythmias and systolic and diastolic dysfunction. Nonetheless, there is still an ongoing controversy on whether the association between 


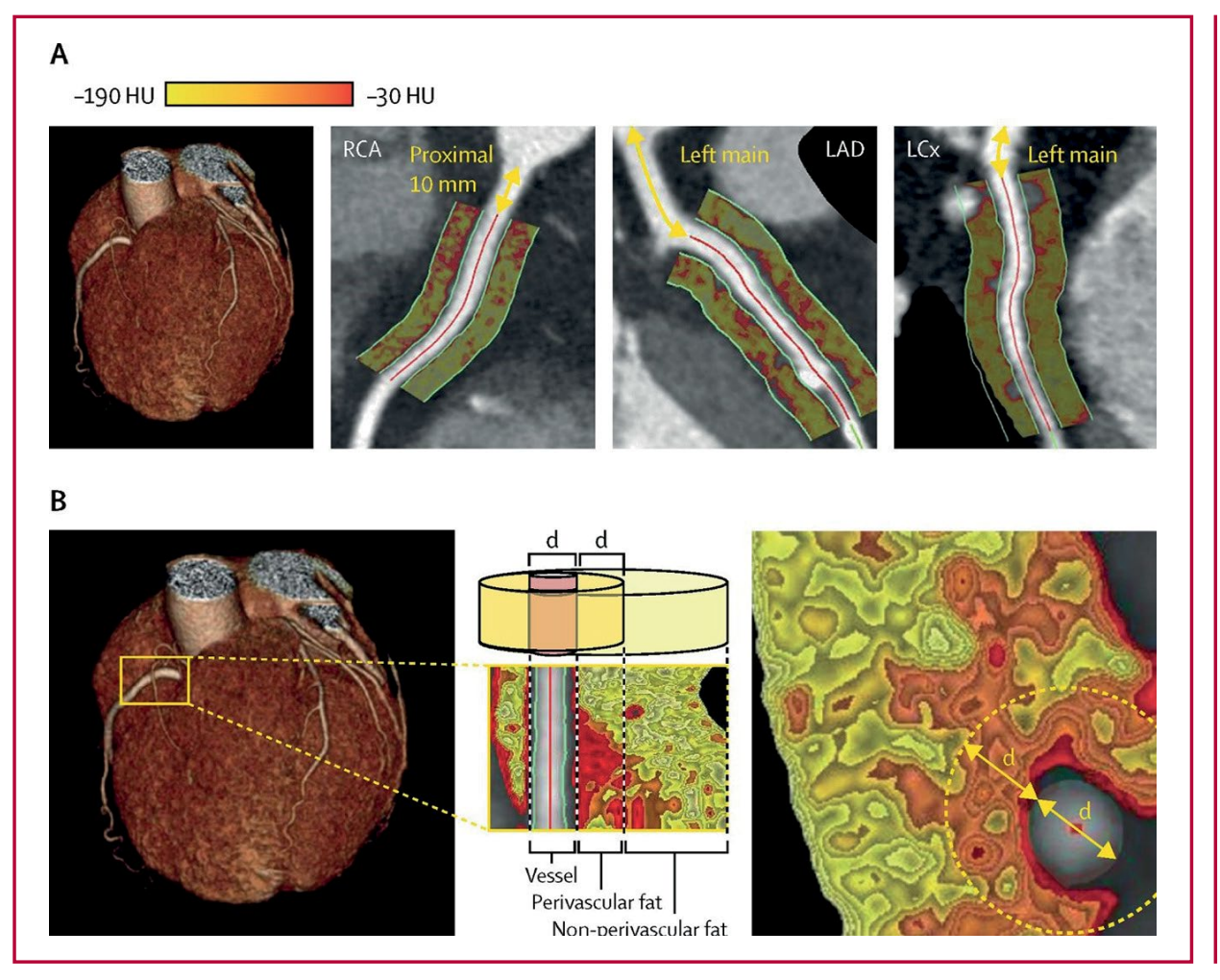

Fig. 6. A) Pericoronary fat attenuation (FAI) of the three main epicardial coronary artery proximal segments, with the corresponding FAl maps. B) Example of pericoronary FAl phenotype around the proximal segment of the right coronary artery. Pericoronary fat was defined as fat located at a radial distance equal to the vessel diameter (d). HU: Hounsfield units. LAD: Left anterior descending artery. LCx: Circumflex artery. RCA: Right coronary artery. (From: Oikonomou EK, et al. Lancet 2018, 392(10151):929-939).

NAFL and cardiovascular disease is a consequence of multiple shared risk factors, or else NAFL independently contributes to cardiovascular disease. Moreover, although steatohepatitis is related to an increased risk of events, this relationship is not well established regarding simple steatosis. (90)

In a recent meta-analysis including 83,395 patients from 26 studies, NAFL was independently associated with the presence of subclinical atheromatosis assessed by carotid Doppler, calcium score, arterial stiffness or endothelial dysfunction (OR 1.6; 95\% CI 1.45-1.78). (91) Specifically, in the 13 studies which included 12,269 patients evaluated by carotid Doppler, NAFL was associated with greater risk of pathological studies (OR 1.74; 95\% CI 1.47-2.06; $\mathrm{p}<0.00001$ ); and in the 7 studies including 29,531 patients with unenhanced CT scan, NAFL was associated with increased calcium score (OR 1.40; 95\% CI 1.22-1.60; $\mathrm{p}=0.02$ ). In another meta-analysis which included 16 studies with 34,043 patients with median follow-up of 6.9 years, Tagher et al. identified a significant relationship between NAFL and the occurrence of fatal and/ or non-fatal cardiovascular events (HR 1.64, 95\% CI 1.26-2.13. (92) In addition, patients with severe NAFL (steatosis and fibrosis) presented higher cardiovascular mortality (OR 3.28; 95\% CI 2.26-4.77), possibly linked to chronic inflammation. (92)

Future perspectives

One of the interesting features of NAFL which is different from coronary artery disease, is its dynamic, and up to a certain point reversible, character. A de- crease of $3 \%$ in body weight is associated with histological improvement in NAFL patients, though weight reduction must be greater than $7 \%$ and $10 \%$ to improve non-alcoholic hepatic steatosis and fibrosis, respectively. Nevertheless, the question on whether the decrease in steatosis could be used as a marker of cardiovascular risk reduction remains open.

An interesting aspect of the relationship between fat depots and cardiovascular events is the difference between sexes. There is a well-known relationship between male sex and risk of cardiovascular events. Even though the mechanisms that link them are not well established, the difference in risk between sexes could be attributed to the fact that women, despite having higher fat content, have more subcutaneous fat and a significantly lower proportion of visceral fat than men. (93) Overall, the evaluation of the extension and composition of regional fat depots could not only help to elucidate these sex differences in the near future, but also improve and personalize risk stratification, identifying patients with elevated residual risk related with inflammation. Considering the accuracy, quantitative and qualitative assessment, cost and availability of current diagnostic methods, CT emerges as the most appropriate modality for risk stratification, specially as it allows the joint assessment of fat depots and atheromatosis extension.

Regarding feasibility, the emergent incorporation of automatic calculation tools, assisted by machine learning, will probably allow consistent and reproducible measurements of regional fat depots, regardless of the type of acquisition and interpretation, favoring 
their incorporation in clinical practice in the near future. (65)

Despite the described associations with atheromatosis and cardiovascular risk, epicardial fat and NAFL are rarely considered as risk markers in clinical practice. Although biochemical studies clearly indicate the risk these tissues imply for cardiovascular health, their study is hampered by the complexity and inaccessibility to assess them from tissue samples. Due to their possibility of simultaneous and complementary evaluation through a single noninvasive imaging modality, the calcium score or CTCA could become, in the forthcoming future, prognostic tools that might reflect the current cardiometabolic state and dynamic/ reversible changes (steatosis), as well as chronic structural changes (coronary calcification). Part of this dynamic and differential character between HS and EAT was reported in a recent study of 1,250 patients between 35 and 74 years, with unenhanced thorax CT scan, where despite significant associations between HS and both CAC and PFV, the only predictors of allcause mortality were CAC and EFV. (68).

\section{Conflicts of interest}

None declared.

(See authors' conflicts of interest forms on the website/ Supplementary material)

\section{REFERENCES}

1. Mahabadi AA, Lehmann N, Kalsch H, Bauer M, Dykun I, Kara K, et al. Association of epicardial adipose tissue and left atrial size on non-contrast CT with atrial fibrillation: the Heinz Nixdorf Recall Study. Eur Heart J Cardiovasc Imaging 2014;15:863-9. https://doi. org/10.1093/ehjci/jeu006

2. Mahabadi AA, Massaro JM, Rosito GA, Levy D, Murabito JM, Wolf PA, et al. Association of pericardial fat, intrathoracic fat, and visceral abdominal fat with cardiovascular disease burden: the Framingham Heart Study. Eur Heart J 2009;30:850-6. https://doi.org/10.1093/eurheartj/ehn573

3. Rosito GA, Massaro JM, Hoffmann U, Ruberg FL, Mahabadi AA, Vasan RS, et al. Pericardial fat, visceral abdominal fat, cardiovascular disease risk factors, and vascular calcification in a community-based sample: the Framingham Heart Study. Circulation 2008, 117:605-13. https://doi.org/10.1161/CIRCULATIONAHA.107.743062

4. Sung KT, Kuo R, Sun JY, Hung TC, Chang SC, Liu CC, et al. Associations between CT-determined visceral fat burden, hepatic steatosis, circulating white blood cell counts and neutrophil-to-lymphocyte ratio. PloS One 2018; 13:e0207284. https://doi.org/10.1371/journal. pone.0207284

5. Barchuk M, Schreier L, Lopez G, Cevey A, Baldi J, Fernandez Tome MDC, et al. Glycosylphosphatidylinositol-anchored high density lipoprotein-binding protein 1 and angiopoietin-like protein 4 are associated with the increase of lipoprotein lipase activity in epicardial adipose tissue from diabetic patients. Atherosclerosis 2019;288:51-9. https://doi.org/10.1016/j.atherosclerosis.2019.06.915 6. Milanese G, Silva M, Bruno L, Goldoni M, Benedetti G, Rossi E, et al. Quantification of epicardial fat with cardiac CT angiography and association with cardiovascular risk factors in symptomatic patients: from the ALTER-BIO (Alternative Cardiovascular Bio-Imaging markers) registry. Diagnost Intervent Radiol 2019;25:35-41. https:// doi.org/10.5152/dir.2018.18037

7. Li Y, Liu B, Li Y, Jing X, Deng S, Yan Y, et al. Epicardial fat tissue in patients with diabetes mellitus: a systematic review and metaanalysis. Cardiovasc Diabetol 2019;18:3. https://doi.org/10.1186/ s12933-019-0807-3
8. Hwang IC, Park HE, Choi SY. Epicardial Adipose Tissue Contributes to the Development of Non-Calcified Coronary Plaque: A 5-Year Computed Tomography Follow-up Study. J Atheroscler Thrombosis 2017;24:262-74. https://doi.org/10.5551/jat.36467

9. Rodriguez-Granillo GA, Carrascosa P, Deviggiano A, Capunay C, De Zan MC, Goldsmit A, et al. Pericardial fat volume is related to atherosclerotic plaque burden rather than to lesion severity. Eur Heart J Cardiovasc Imaging 2017; 18:795-801. https://doi. org/10.1093/ehjci/jew139

10. Nakamori S, Nezafat M, Ngo LH, Manning WJ, Nezafat R. Left Atrial Epicardial Fat Volume Is Associated With Atrial Fibrillation: A Prospective Cardiovascular Magnetic Resonance 3D Dixon Study. J Am Heart Assoc 2018;7:e008232. https://doi.org/10.1161/ JAHA.117.008232

11. Zhu W, Zhang H, Guo L, Hong K. Relationship between epicardial adipose tissue volume and atrial fibrillation : A systematic review and meta-analysis. Herz 2016;41:421-7. https://doi.org/10.1007/ s00059-015-4387-z

12. Iantorno M, Soleimanifard S, Schar M, Brown TT, Bonanno G, Barditch-Crovo P, et al. Regional coronary endothelial dysfunction is related to the degree of local epicardial fat in people with HIV. Atherosclerosis 2018;278:7-14. https://doi.org/10.1016/j.atherosclerosis.2018.08.002

13. Nakanishi K, Fukuda S, Tanaka A, Otsuka K, Taguchi H, Shimada K. Relationships Between Periventricular Epicardial Adipose Tissue Accumulation, Coronary Microcirculation, and Left Ventricular Diastolic Dysfunction. Can J Cardiol 2017;33:1489-97. https:// doi.org/10.1016/j.cjca.2017.08.001

14. Oikonomou EK, Marwan M, Desai MY, Mancio J, Alashi A, Hutt Centeno E, et al. Non-invasive detection of coronary inflammation using computed tomography and prediction of residual cardiovascular risk (the CRISP CT study): a post-hoc analysis of prospective outcome data. Lancet 2018,392:929-39. https://doi.org/10.1016/ S0140-6736(18)31114-0

15. Oikonomou EK, Williams MC, Kotanidis CP, Desai MY, Marwan M, Antonopoulos AS, Thomas KE, Thomas S, Akoumianakis I, Fan LM et al: A novel machine learning-derived radiotranscriptomic signature of perivascular fat improves cardiac risk prediction using coronary CT angiography. Eur Heart J 2019;40:3529-43. https://doi. org/10.1093/eurheartj/ehz592

16. Rodriguez-Granillo GA, Capunay C, Deviggiano A, De Zan M, Carrascosa P. Regional differences of fat depot attenuation using noncontrast, contrast-enhanced, and delayed-enhanced cardiac CT. Acta Radiol 2019;60:459-67. https://doi.org/10.1177/0284185118787356

17. Charlton MR, Burns JM, Pedersen RA, Watt KD, Heimbach JK, Dierkhising RA. Frequency and outcomes of liver transplantation for nonalcoholic steatohepatitis in the United States. Gastroenterol 2011;141:1249-53. https://doi.org/10.1053/j.gastro.2011.06.061

18. Yki-Jarvinen $H$. Non-alcoholic fatty liver disease as a cause and a consequence of metabolic syndrome. Lancet Diabetes Endocrinol 2014;2:901-10. https://doi.org/10.1016/S2213-8587(14)70032-4

19. Ridker PM, Everett BM, Thuren T, MacFadyen JG, Chang WH, Ballantyne C, et al. Antiinflammatory Therapy with Canakinumab for Atherosclerotic Disease. N Engl J Med 2017;377:1119-31. https:// doi.org/10.1056/NEJMoa1707914

20. Bohula EA, Giugliano RP, Leiter LA, Verma S, Park JG, Sever PS, et al. Inflammatory and Cholesterol Risk in the FOURIER Trial. Circulation 2018;138:131-40. https://doi.org/10.1161/CIRCULATIONAHA.118.034032

21. Bhatt DL, Steg PG, Miller M, Brinton EA, Jacobson TA, Ketchum SB, et al. Cardiovascular Risk Reduction with Icosapent Ethyl for Hypertriglyceridemia. N Engl J Med 2019;380:11-22. https://doi. org/10.1056/NEJMoa1812792

22. Ortega FB, Lavie CJ, Blair SN. Obesity and Cardiovascular Disease. Circulation Res 2016;118:1752-70. https://doi.org/10.1161/CIRCRESAHA.115.306883

23. Koliaki C, Liatis S, Kokkinos A. Obesity and cardiovascular disease: revisiting an old relationship. Metabolism: clinical and experimental 2019;92:98-107. https://doi.org/10.1016/j.metabol.2018.10.011

24. Mehta T, Fontaine KR, Keith SW, Bangalore SS, de los Campos G, Bartolucci A, Pajewski NM, Allison DB. Obesity and mortality: are the risks declining? Evidence from multiple prospective studies in the United States. Obes Rev 2014;15:619-29. https://doi.org/10.1111/ obr.12191 
25. Sharma A, Vallakati A, Einstein AJ, Lavie CJ, Arbab-Zadeh A, Lopez-Jimenez F, et al. Relationship of body mass index with total mortality, cardiovascular mortality, and myocardial infarction after coronary revascularization: evidence from a meta-analysis. Mayo Clin Proc 2014; 89:1080-100. https://doi.org/10.1016/j. mayocp.2014.04.020

26. Antonopoulos AS, Oikonomou EK, Antoniades C, Tousoulis D. From the BMI paradox to the obesity paradox: the obesity-mortality association in coronary heart disease. Obes Rev 2016;17:989-1000. https://doi.org/10.1111/obr. 12440

27. Mukherjee D, Ojha C. Obesity Paradox in Contemporary Cardiology Practice. JACC Cardiovasc interv 2017;10:1293-4. https://doi. org/10.1016/j.jcin.2017.03.048

28. Wells JC. Commentary: The paradox of body mass index in obesity assessment: not a good index of adiposity, but not a bad index of cardio-metabolic risk. Int J Epidemiol 2014;43:672-4. https://doi. org/10.1093/ije/dyu060

29. Puig T, Ferrero-Gregori A, Roig E, Vazquez R, Gonzalez-Juanatey JR, Pascual-Figal D, et al. Prognostic value of body mass index and waist circumference in patients with chronic heart failure (Spanish REDINSCOR Registry). Rev Esp Cardiol (Engl Ed) 2014; 67:101-6. https://doi.org/10.1016/j.recesp.2013.06.025

30. Rodriguez-Granillo GA, Carrascosa P. Abdominal Obesity as a Risk Predictor: Closer Than Body Mass Index But Not Close Enough. J Am Coll Cardiol 2018;71:1398-9. https://doi.org/10.1016/j. jacc.2017.12.065

31. Rao VN, Zhao D, Allison MA, Guallar E, Sharma K, Criqui $\mathrm{MH}$, et al. Adiposity and Incident Heart Failure and its Subtypes: MESA (Multi-Ethnic Study of Atherosclerosis). JACC Heart Fail 2018;6:999-1007. https://doi.org/10.1016/j.jchf.2018.07.009

32. Antonopoulos AS, Antoniades C. The role of epicardial adipose tissue in cardiac biology: classic concepts and emerging roles. J Physiol 2017;595:3907-17. https://doi.org/10.1113/JP273049

33. Iacobellis G. Epicardial fat: a new cardiovascular therapeutic target. Curr Opin Pharmacol 2016;27:13-8. https://doi.org/10.1016/j. coph.2016.01.004

34. Cherian S, Lopaschuk GD, Carvalho E. Cellular cross-talk between epicardial adipose tissue and myocardium in relation to the pathogenesis of cardiovascular disease. Am J Physiol Endocrinol Metabol 2012;303:E937-49. https://doi.org/10.1152/ajpendo.00061.2012 35. Fitzgibbons TP, Czech MP. Epicardial and perivascular adipose tissues and their influence on cardiovascular disease: basic mechanisms and clinical associations. J Am Heart Assoc 2014;3(2):e000582. https://doi.org/10.1161/JAHA.113.000582

36. Bucerius J, Mani V, Wong S, Moncrieff C, Izquierdo-Garcia D, Machac J, et al. Arterial and fat tissue inflammation are highly correlated: a prospective 18F-FDG PET/CT study. Eur J Nucl Med Mol Imaging 2014;41:934-45. https://doi.org/10.1007/s00259-013-2653-y 37. Antonopoulos AS, Sanna F, Sabharwal N, Thomas S, Oikonomou EK, Herdman L, et al. Detecting human coronary inflammation by imaging perivascular fat. Sci Transl Med 2017;9:938. https:/doi. org/10.1126/scitranslmed.aal2658

38. Packer M. Epicardial Adipose Tissue May Mediate Deleterious Effects of Obesity and Inflammation on the Myocardium. J Am Coll Cardiol 2018: 71:2360-72. https://doi.org/10.1016/j.jacc.2018.03.509 39. Viskovic K, Zidovec Lepej S, Gorenec A, Grgic I, Lukas D, et al. Cardiovascular markers of inflammation and serum lipid levels in HIV-infected patients with undetectable viremia. Sci Rep 2018;8:6113. https://doi.org/10.1038/s41598-018-24446-4

40. Lima-Martinez MM, Campo E, Salazar J, Paoli M, Maldonado I, Acosta C, et al. Epicardial fat thickness as cardiovascular risk factor and therapeutic target in patients with rheumatoid arthritis treated with biological and nonbiological therapies. Arthritis 2014;782850. https://doi.org/10.1155/2014/782850

41. Wang X, Guo Z, Zhu Z, Bao Y, Yang B. Epicardial fat tissue in patients with psoriasis:a systematic review and meta-analysis. Lipids Health Dis 2016, 15:103. https://doi.org/10.1186/s12944-016-0271-y 42. Chatzizisis YS, Giannoglou GD. Myocardial bridges spared from atherosclerosis: overview of the underlying mechanisms. Can J Cardiol 2009,25:219-22. https://doi.org/10.1016/S0828-282X(09)70065-0 43. Rodriguez-Granillo GA, Rosales MA, Pugliese F, FernandezPereira C, Rodriguez AE Prevalence and characteristics of major and minor coronary artery anomalies in an adult population assessed by computed tomography coronary angiography. EuroIntervention
2009;4:641-7. https://doi.org/10.4244/EIJV4I5A107

44. McKenney ML, Schultz KA, Boyd JH, Byrd JP, Alloosh M, Teague SD, et al. Epicardial adipose excision slows the progression of porcine coronary atherosclerosis. J Cardiothorac Surg 2014;9:2. https://doi.org/10.1186/1749-8090-9-2

45. Hirata Y, Tabata M, Kurobe H, Motoki T, Akaike M, Nishio C, et al. Coronary atherosclerosis is associated with macrophage polarization in epicardial adipose tissue. J Am Coll Cardiol 2011;58:248-55. https://doi.org/10.1016/j.jacc.2011.01.048

46. Miksztowicz V, Morales C, Barchuk M, Lopez G, Poveda R, Gelpi $\mathrm{R}$, et al. Metalloproteinase 2 and 9 Activity Increase in Epicardial Adipose Tissue of Patients with Coronary Artery Disease. Curr Vasc Pharmacol 2017;15:135-43. https://doi.org/10.2174/15701611146661 61024124244

47. Bouchi R, Takeuchi T, Akihisa M, Ohara N, Nakano Y, Nishitani $R$, et al: High visceral fat with low subcutaneous fat accumulation as a determinant of atherosclerosis in patients with type 2 diabetes. Cardiovasc Diabetol 2015;14:136. https://doi.org/10.1186/s12933015-0302-4

48. Ladeiras-Lopes R, Sampaio F, Bettencourt N, Fontes-Carvalho R, Ferreira N, Leite-Moreira A, et al. The Ratio Between Visceral and Subcutaneous Abdominal Fat Assessed by Computed Tomography Is an Independent Predictor of Mortality and Cardiac Events. Rev Esp Cardiol (Engl Ed) 2017;70:331-7. https://doi.org/10.1016/j. recesp.2016.09.006

49. Rodriguez-Granillo GA, Reynoso E, Capunay C, Carpio J, Carrascosa P. Pericardial and visceral, but not total body fat, are related to global coronary and extra-coronary atherosclerotic plaque burden. Int J Cardiol 2018;260:204-10. https://doi.org/10.1016/j.ijcard.2018.01.106

50. Mazurek T, Zhang L, Zalewski A, Mannion JD, Diehl JT, Arafat $\mathrm{H}$, et al: Human epicardial adipose tissue is a source of inflammatory mediators. Circulation 2003;108:2460-6. https://doi.org/10.1161/01. CIR.0000099542.57313.C5

51. Barchuk M, Dutour A, Ancel P, Svilar L, Miksztowicz V, Lopez G, et al. Untargeted Lipidomics Reveals a Specific Enrichment in Plasmalogens in Epicardial Adipose Tissue and a Specific Signature in Coronary Artery Disease. Arterioscl Thromb Vasc Biol 2020;40:9861000. https://doi.org/10.1161/ATVBAHA.120.313955

52. Donnelly KL, Smith CI, Schwarzenberg SJ, Jessurun J, Boldt MD, Parks EJ. Sources of fatty acids stored in liver and secreted via lipoproteins in patients with nonalcoholic fatty liver disease. J Clin investig 2005;115:1343-51. https://doi.org/10.1172/JCI23621

53. Chalasani N, Younossi Z, Lavine JE, Charlton M, Cusi K, Rinella $\mathrm{M}$, et al. The diagnosis and management of nonalcoholic fatty liver disease: Practice guidance from the American Association for the Study of Liver Diseases. Hepatol 2018; 67:328-57. https://doi. org/10.1002/hep. 29367

54. Gastaldelli A, Toschi E, Pettiti M, Frascerra S, Quinones-Galvan A, Sironi AM, et al. Effect of physiological hyperinsulinemia on gluconeogenesis in nondiabetic subjects and in type 2 diabetic patients. Diabetes 2001;50:1807-12. https://doi.org/10.2337/diabetes.50.8.1807

55. Bugianesi E, Gastaldelli A, Vanni E, Gambino R, Cassader M, Baldi S. Insulin resistance in non-diabetic patients with non-alcoholic fatty liver disease: sites and mechanisms. Diabetol 2005;48:63442. https://doi.org/10.1007/s00125-005-1682-x

56. Gaggini M, Morelli M, Buzzigoli E, DeFronzo RA, Bugianesi E, Gastaldelli A. Non-alcoholic fatty liver disease (NAFLD) and its connection with insulin resistance, dyslipidemia, atherosclerosis and coronary heart disease. Nutrients 2013;5:1544-60. https://doi. org/10.3390/nu5051544

57. Luo ZX, Zeng Q, Luo R, Wang Y, Ge Q. Relative Contributions of Ectopic Liver and Abdominal Fat Accumulation to Arterial Stiffness. Endocr Pract 2015; 21:574-80. https://doi.org/10.4158/EP14526.OR 58. Lucero D, Zago V, Lopez GI, Graffigna M, Lopez GH, Fainboim H, et al. Does non-alcoholic fatty liver impair alterations of plasma lipoproteins and associated factors in metabolic syndrome? Clin Chim Acta 2011;412:587-92. https://doi.org/10.1016/j.cca.2010.12.012

59. Lucero D, Miksztowicz V, Gualano G, Longo C, Landeira G, Alvarez E, et al. Nonalcoholic fatty liver disease associated with metabolic syndrome: Influence of liver fibrosis stages on characteristics of very low-density lipoproteins. Clin Chim Acta 2017;473:1-8. https:// doi.org/10.1016/j.cca.2017.08.006 
60. Stefan N, Kantartzis K, Haring HU. Causes and metabolic consequences of Fatty liver. Endocrin Rev 2008;29:939-60. https://doi. org/10.1210/er.2008-0009

61. Targher G, Chonchol M, Miele L, Zoppini G, Pichiri I, Muggeo M. Nonalcoholic fatty liver disease as a contributor to hypercoagulation and thrombophilia in the metabolic syndrome. Semin Thromb Hemost 2009;35:277-87. https://doi.org/10.1055/s-0029-1222606 62. Simon TG, Trejo MEP, McClelland R, Bradley R, Blaha MJ, Zeb I, et al. Circulating Interleukin-6 is a biomarker for coronary atherosclerosis in nonalcoholic fatty liver disease: Results from the MultiEthnic Study of Atherosclerosis. Int J Cardiol 2018;259:198-204. https://doi.org/10.1016/j.ijcard.2018.01.046

63. Campbell PT, VanWagner LB, Colangelo LA, Lewis CE, Henkel A, Ajmera VH, et al. Association between plasminogen activator inhibitor-1 in young adulthood and nonalcoholic fatty liver disease in midlife: CARDIA. Liver int 2020;40:1111-20. https://doi.org/10.1111/ liv. 14417

64. Marwan M, Achenbach S. Quantification of epicardial fat by computed tomography: why, when and how? J Cardiovasc Comput Tomogr 2013,7:3-10. https://doi.org/10.1016/j.jcct.2013.01.002 65. Commandeur F, Goeller M, Razipour A, Cadet S, Hell MM, Kwiecinski J, et al. Fully Automated CT Quantification of Epicardial Adipose Tissue by Deep Learning: A Multicenter Study. Radiol Artif intellig 2019;1:e190045. https://doi.org/10.1148/ryai.2019190045

66. La Grutta L, Toia P, Farruggia A, Albano D, Grassedonio E, Palmeri A, et al.Quantification of epicardial adipose tissue in coronary calcium score and CT coronary angiography image data sets: comparison of attenuation values, thickness and volumes. Br J Radiol 2016;89:20150773. https://doi.org/10.1259/bjr.20150773

67. Nagayama Y, Nakamura N, Itatani R, Oda S, Kusunoki S, Takahashi $\mathrm{H}$, et al. Epicardial fat volume measured on nongated chest CT is a predictor of coronary artery disease. Eur Radiol 2019;29:363846. https://doi.org/10.1007/s00330-019-06079-x

68. Rodriguez-Granillo GA, Reynoso E, Capunay C, Antoniades C, Shaw LJ, Carrascosa P. Prognostic Value of Vascular Calcifications and Regional Fat Depots Derived From Conventional Chest Computed Tomography. J Thoracic Imaging 2019;34:33-40. https://doi. org/10.1097/RTI.0000000000000370

69. Iacobellis G, Corradi D, Sharma AM. Epicardial adipose tissue: anatomic, biomolecular and clinical relationships with the heart. Nat Clin Pract Cardiovasc Med 2005;2:536-43. https://doi.org/10.1038/ ncpcardio0319

70. Cheng VY, Dey D, Tamarappoo B, Nakazato R, Gransar H, Miranda-Peats R, et al. Pericardial fat burden on ECG-gated noncontrast $\mathrm{CT}$ in asymptomatic patients who subsequently experience adverse cardiovascular events. JACC Cardiovasc Imaging 2010;3:352-60. https://doi.org/10.1016/j.jcmg.2009.12.013

71. Li Q, Dhyani M, Grajo JR, Sirlin C, Samir AE.Current status of imaging in nonalcoholic fatty liver disease. World $\mathrm{J}$ Hepatol 2018;10:530-42. https://doi.org/10.4254/wjh.v10.i8.530

72. Al Chekakie MO, Welles CC, Metoyer R, Ibrahim A, Shapira AR, Cytron J,et al. Pericardial fat is independently associated with human atrial fibrillation. J Am Coll Cardiol2010;56:784-8. https://doi. org/10.1016/j.jacc.2010.03.071

73. Iacobellis G, Leonetti F, Singh N, A MS.Relationship of epicardial adipose tissue with atrial dimensions and diastolic function in morbidly obese subjects. Int J Cardiol 2007;115:272-3. https://doi. org/10.1016/j.ijcard.2006.04.016

74. Wong CX, Abed HS, Molaee P, Nelson AJ, Brooks AG, Sharma G, et al. Pericardial fat is associated with atrial fibrillation severity and ablation outcome. J Am Coll Cardiol 2011;57:1745-51. https:// doi.org/10.1016/j.jacc.2010.11.045

75. van Woerden G, Gorter TM, Westenbrink BD, Willems TP, van Veldhuisen DJ, Rienstra M. Epicardial fat in heart failure patients with mid-range and preserved ejection fraction. Eur J Heart Fail 2018;20:1559-66. https://doi.org/10.1002/ejhf.1283

76. Venteclef N, Guglielmi V, Balse E, Gaborit B, Cotillard A, Atassi F, et al. Human epicardial adipose tissue induces fibrosis of the atrial myocardium through the secretion of adipo-fibrokines. Eur Heart $\mathbf{J}$ 2015;36:795-805a. https://doi.org/10.1093/eurheartj/eht099

77. Ng ACT, Strudwick M, van der Geest RJ, Ng ACC, Gillinder L, Goo SY, et al. Impact of Epicardial Adipose Tissue, Left Ventricular
Myocardial Fat Content, and Interstitial Fibrosis on Myocardial Contractile Function. Circulation Cardiovasc Imaging 2018:11:e007372. https://doi.org/10.1161/CIRCIMAGING.117.007372

78. Brener M, Ketlogetswe K, Budoff M, Jacobson LP, Li X, Rezaeian $\mathrm{P}$, et al. Epicardial fat is associated with duration of antiretroviral therapy and coronary atherosclerosis. Aids 2014;28:1635-44. https:// doi.org/10.1097/QAD.0000000000000116

79. Mahabadi AA, Berg MH, Lehmann N, Kalsch H, Bauer M, Kara $\mathrm{K}$, et al. Association of epicardial fat with cardiovascular risk factors and incident myocardial infarction in the general population: the Heinz Nixdorf Recall Study. J Am Coll Cardiol 2013;61:1388-95. https://doi.org/10.1016/j.jacc.2012.11.062

80. Ding J, Hsu FC, Harris TB, Liu Y, Kritchevsky SB, Szklo M, et al: The association of pericardial fat with incident coronary heart disease: the Multi-Ethnic Study of Atherosclerosis (MESA). Am J Clin Nut 2009;90:499-504. https://doi.org/10.3945/ajcn.2008.27358 81. Larsen BA, Laughlin GA, Saad SD, Barrett-Connor E, Allison MA, Wassel CL. Pericardial fat is associated with all-cause mortality but not incident CVD: the Rancho Bernardo Study. Atherosclerosis 2015;239:470-5. https://doi.org/10.1016/j.atherosclerosis.2015.02.022

82. Goeller M, Achenbach S, Marwan M, Doris MK, Cadet S, Commandeur F, et al. Epicardial adipose tissue density and volume are related to subclinical atherosclerosis, inflammation and major adverse cardiac events in asymptomatic subjects. J Cardiovasc Comp Tomogr 2018;12:67-73. https://doi.org/10.1016/j.jcct.2017.11.007

83. Rodriguez-Granillo GA, Carrascosa P, Bruining N, Waksman R, Garcia-Garcia HM. Defining the non-vulnerable and vulnerable patients with computed tomography coronary angiography: evaluation of atherosclerotic plaque burden and composition. Eur Heart J Cardiovasc Imaging 2016;17:481-91. https://doi.org/10.1093/ehjci/ jew012

84. Nerlekar N, Brown AJ, Muthalaly RG, Talman A, Hettige T, Cameron JD, et al. Association of Epicardial Adipose Tissue and High-Risk Plaque Characteristics: A Systematic Review and MetaAnalysis. J Am Heart Assoc 2017;6:e06379 https://doi.org/10.1161/ JAHA.117.006379

85. Goeller M, Achenbach S, Cadet S, Kwan AC, Commandeur F, Slomka PJ, et al. Pericoronary Adipose Tissue Computed Tomography Attenuation and High-Risk Plaque Characteristics in Acute Coronary Syndrome Compared With Stable Coronary Artery Disease. JAMA Cardiol 2018:3:858-63. https://doi.org/10.1001/jamacardio. 2018.1997

86. Oikonomou EK, Antoniades C. The role of adipose tissue in cardiovascular health and disease. Nat Rev Cardiol 2019;16:83-99. https://doi.org/10.1038/s41569-018-0097-6

87. Rinella ME. Nonalcoholic fatty liver disease: a systematic review. JAMA 2015;313:2263-73. https://doi.org/10.1001/jama.2015.5370

88. McPherson S, Hardy T, Henderson E, Burt AD, Day CP, Anstee QM. Evidence of NAFLD progression from steatosis to fibrosingsteatohepatitis using paired biopsies: implications for prognosis and clinical management. J Hepatol 2015; 62:1148-55. https://doi. org/10.1016/j.jhep.2014.11.034

89. Ekstedt M, Franzen LE, Mathiesen UL, Thorelius L, Holmqvist M, Bodemar G, et al. Long-term follow-up of patients with NAFLD and elevated liver enzymes. Hepatology 2006;44:865-73. https://doi. org $/ 10.1002 /$ hep. 21327

90. Targher G, Day CP, Bonora E. Risk of cardiovascular disease in patients with nonalcoholic fatty liver disease. New Engl J Med 2010;363:1341-50. https://doi.org/10.1056/NEJMra0912063

91. Zhou YY, Zhou XD, Wu SJ, Fan DH, Van Poucke S, Chen YP, et al. Nonalcoholic fatty liver disease contributes to subclinical atherosclerosis: A systematic review and meta-analysis. Hepatol Commun 2018;2:376-92. https://doi.org/10.1002/hep4.1155

92. Targher G, Byrne CD, Lonardo A, Zoppini G, Barbui C. Non-alcoholic fatty liver disease and risk of incident cardiovascular disease: A meta-analysis. J Hepatol 2016:65:589-600. https://doi.org/10.1016/j. jhep.2016.05.013

93. Camhi SM, Bray GA, Bouchard C, Greenway FL, Johnson WD, Newton RL, et al. The relationship of waist circumference and BMI to visceral, subcutaneous, and total body fat: sex and race differences. Obesity 2011;19:402-8. https://doi.org/10.1038/oby.2010.248 